they had left school with such a knowledge of the classics as to have been considered good scholars at the time, can it be seriously expected that at the expiration of six or seven years, devoted to other subjects, they shall be found competent to undergo such strict examinations in the classics as would be required, at either of our universities, after a residence there of four years, with a constant application to the dead languages? It must not be forgotten, also, that a member cannot become a fellow without an extended medical education, and thereby to distinguish himself, and the very key to his distinction becomes the bane and antidote of his classical learning, which is requisite for this critical examination; in other words, two jealous mistresses require his undivided attention, neither being satisfied by half-and-half attentions. He cannot devote his time to both. In addition to this, I consider the law relating to the fellowship a retrospective one to members of the present time, and one which is arbitrary and unjust.

I will next inquire what such an examination has to do with the usual and strict examinations of the professors of the College, or of what avail such an examination can be to the profound anatomist, the skilful surgeon, or the general practitioner? or does it make either one tittle the better man? The patient does not require his medical man to be a classical critic or a lecturer on the languages. I should have thought, if it were so, it would be wiser to make such acquirements precede the medical education, and that a degree of A.B. at one of the universities be a sine quâ non to admission to the hospital or lecture-room. But after all, is a high classical education necessary to constitute the skilful and successful?which, Sir, I submit to the profession, ought to be the sole claim to the honour of a fellowship. Why, then, force the practitioner who now has the certificate of the College as a proof of his fitness to undergo this extraordinary examination, before you allow him to come into the College, which seems, as it were, the "ultimum bonum," because, as far as the public are concerned, if he is fit to be sent before the public as a member, he is as a fellow. It is the treatment of the schoolboy, if you say your lesson well, you shall have a seat on this stool-"ut olim pueri crusticula dant Blandi Doctores." A great cause is generally undertaken as a public good, and if the rank of fellow either confers a boon on the public or a benefit to society, it can only be so as a token of high approbation of the College; if so, why not reserve it for such men who have received the testimony of honour from the public, or have done some good for humanity, or effected a blessing to the state, or in some way distinguished themselves; then, and not until then, will the degree of fellow of the Royal College of Surgeons be esteemed by the public as a credit to the holder, as a mark of distinction in that particular branch of skill and learning over which the College is constituted to preside and to judge. Let the College require the highest qualifications in that branch over which they preside, and not intermeddle with other acquirements foreign to their establishment, lest the public should be at a loss to know whether Mr. A. B. is made fellow for his skill in surgery or his attainments as a classical scholar. Having, Sir, endeavoured to expose the futility of the present system, allow me to make a few suggestions, which, though coming from a humble individual, are yet based on such grounds as will afford the best proofs of qualification-viz., let the College require of the medical student about to enter the profession evidence of a sound classical education, either by his having graduated in arts at one of the universities, or by his submitting to a fair examination, at which time, if not found proficient, they may with propriety say, "Boy, go back to school;" or, having gone through this examination, then, and not till then, let him enter to his medical education, and in due course admit him to the membership, after which, should he either distinguish himself in his calling or otherwise, give him the highest rank, as a mark of their esteem and respect, and make him a fellow.

February 14, 1850.

I am, Sir, \&c.

\section{THE COLLEGE OF SURGEONS AND THE} PROJECTED COLLEGE.

\section{To the Editor of ThE LANceT.}

$\mathrm{SIR}_{\mathrm{I},-T h e}$ present moment is a critical one for the medical profession; I feel anxious, therefore, through the pages of your journal, to address a few words of advice to my fellowmembers of the College of Surgeons.

To what, I would ask, are we to attribute all the disunion, the conflicting interests, and petty jealousies, that have so long prevailed throughout the medical profession, weakening its collective influence, lowering it in public estimation, and retarding the advancement of medical and surgical science by withholding from the meritorious those distinctions of rank or place which, when properly bestowed, are powerful incentives to exertion. The causes of all these evils are clearly two-first, the multiplicity of medical and surgical institutions; and secondly, their gross mismanagement. Our object, therefore, should be to reduce, not to increase, the number of medical corporations, and to correct those abuses which are the offspring of prejudice and monopoly.

I am not surprised that the members of the College of Sur. geons should feel indignant at the insulting behaviour of the council; it is, indeed, hard to endure patiently the overbearing conduct of self-elected governors, especially when their unworthiness and incapacity are so deeply felt, and so universally acknowledged. I am not surprised, too, that such men as the council of the college, who, with a few honourable ex. ceptions, are so proverbially narrow-minded and selfish-men who, preferring place to character, dishonour their office by retaining it, should feel regardless of the general good of the profession. This is the infirmity of human nature; it is a sad spectacle in men whose professional attainments would otherwise command our respect, and if it provokes our anger, should also claim our pity. The members of the college, however, must not forget their duty, nor suffer themselves to be betrayed by a momentary feeling of irritation and resentment into any act of indiscretion. The College of Surgeons, thongh a badly conducted, is yet a time-honoured institution, and we must neither destroy it ourselves by constructing a rival col lege, nor suffer it to sink lower than it has lately done through the imbecility of its present managers. All our remon. strances with these misguided men have hitherto been in effectual, and nothing now can avert the ruin of the college but the enfranchisement of its members, and a complete remodelling of its present laws; it is to the attainment of these objects, therefore, that all our united efforts should be steadily directed. Let us make our grievances known to the Secretary of State and the present Parliament, and we have every reason to hope that they will be listened to and redressed.

The fellowship, if it is to be conferred on persons who are unworthy of a seat at the council-table, is a bauble not worth our acceptance.

Allow me, Sir, in conclusion, to express my gratitude for your zealous co-operation in the cause we have at heart-viz., the preservation of the college by a well-timed and judicious reform, which, I trust, may yet be effected.

$$
\text { I remain, Sir, }
$$

Your much obliged and obedient servant,

Much-Wenlock, Feb. 26, 1850.

$$
\text { W. P. Brookes. }
$$

\section{QUESTION - SHALL THERE BE CORPORATH REFORM, OR MEDICAL REFORM ? To the Editor of THE LANCET.}

AFTER offering some general remarks on these subjects, the writer observes, that-

Many medical reformers, without doubt, have left the reformation of corporate wrongs entirely to those members of the corporation whom it most concerned; conceiving that this species of reform would have but little effect on the general reformation of the profession. And such reformers as these must be glad to find that at the present moment the great reformation is not in imminent danger of being stifled by soothing the ruffled amour propre of those gentlemen who were discontented with their corporate laws; and that the redress of errors committed in the year of grace 1843 , will not be so complete as to prevent the chance of older errors sharing a better fate, or so "satisfactory to all parties" as to shelve the entire question of medical reform.

I venture to say, then, even at the risk of being considered a promoter of discord, that there are reformers who will not be sorry that the ultimatum of the Council of the College of Surgeons has altered the late tranquil features of the medical reform question, and given another opportunity for all thorough reformers to unite in proclaiming, that whatever the alteration in charters may be, no alteration shall be made in the laws of this country, without the explicit acknowledgment of those great principles of justice which, discarding the interests of the few for that of the many, constitute the foundations of all law, and without which no law can stand.

Although $I$ did not wish to disturb the late negotiations while they were pending, I could not agree with " the Oldest and Staunchest of Medical Reformers," that "a fair prospect of bringing to a final close the long agitated question of medical reform is now before us, and that by our united efforts, 
free from all petty bickerings and jealousies, we may speedily obtain a great triumph for a noble cause." For my own part, I cannot disguise from myself the fact, that there are two antagonistic principles fully at work in this much-talked of reformation of our profession, and that these two principles have not yet been brought fairly face to face.

The principle that would establish a superior, a middle, and an inferior grade in one profession, or rather, that would create two heads and one body, in a tripartite nondescript, is totally opposed to the principle which declares the profession of medicine to be one and indivisible-to be a unity in its study, a unity in its action, and a unity in its object. Being a faithful disciple of the latter principle; and being convinced that no thorough reformation of our profession can ever take place till this principle is fully acknowledged by our laws, I am prepared to do all in my power, both in and out of the profession, to establish its claims to the consideration of all thoughtful men; and with your permission I will, as time and opportunity occur, recur to this subject in the pages of your valuable journal, and till next week permit me to remain, Sir, as ever,

Oxford-terarce, Hyde-park, Feb. 1850. Yours obediently, WILLIAM RoBINS.

\section{ALARMING RESULTS OF CHLOROFORM. To the Editor of 'THE LANCET.}

Srr,-After reading the case of death from chloroform, published in THe LanceT, a few weeks since, by Mr. Solly, it was my intention to have sent you the following. Having omitted to do so, I now offer it, as confirming the treatment recommended by M. Ricord, in his letter, copied into your last number. On July 3 rd of last year, I removed a large scirrhous breast from a strong stout woman, Mrs. K- aged forty-two, the wife of a plumber, of this town. It was her wish that she should be put under the influence of chloroform, which was accordingly done. For several minutes her system resisted the influence of the remedy, and it was not till three drachms were used, and the vapour concentrated by placing a fold of lint over the back of the inhaler, that she was rendered unconscious.

The removal of the breast occupied about four minutes, during which she showed not the slightest consciousness of pain, or of what was going on; just as the last incision was completed, she slipped from the chair in which she was sitting, and from the grasp of an athletic woman who was holding her, and fell apparently dead upon the floor; her face was of a deadly pallid and livid colour, and her lips, lobes of the ears, and finger-nails, of a deep purple hue; her eyes were fixed, pupils rather dilated; irides motionless; her limbs relaxed and perfectly still; no pulse to be felt at the wrist or carotids; and on placing my ear upon her chest, not the slightest sound of the heart's action or respiratory murmur was audible. The window was thrown open, and cold water, ammonia, \&e., called for. I immediately perceived that all these would avail nothing, when it occurred to me that artificial respiration, by direct insufflation,-in the way, indeed, in which $I$ have always used it for resuscitating still-born children, and which I learnt from my midwifery preceptor, the late Dr. Hugh Ley,-might possibly save her. Intervening a single fold of my pocket handkerchief, I placed my lips within hers, and breathed strongly into her mouth, at the same time closing her nostrils with the thumb and forefinger of my left hand, and pressing her larynx towards the spinal column with my right fingers and thumb, so as in some degree to close the oesophagus. At the fourth inspiration she gave a slight convulsive gasp, and this was soon followed by other and more regular respiratory efforts; her pulse returned, and her countenance soon resumed its natural colour, and I had the delightful relief to see her revive. After a few minutes, I proceeded to remove a diseased gland from the axilla; at this she cried out a little; though it was evident that the anæsthetic influence of the chloroform was still to a degree kept up, yet she was quite conscious of what was being done. There had been but little hæmorrhage during the operation, and only one vessel required to be tied. She complained much of headach during the rest of the dav, but went on favourably, and the wound soon healed. She has not shown any symptoms as yet of a return of the disease. I was assisted in the operation by my friends, Mr. Frederick Seagram, of this town, Mr. E. B. Thring, of the Bengal Medical Service, and my own assistant. We all looked on the woman as irrecoverably dead, and were as much surprised as gratified to see her restored.

$I$ remain, Sir, your constant reader,

Warminster, Wilts, Feb. 26, 1850 .

Charles Blemck.

\section{NAVAL ASSISTANT-SURGEONS. To the Editor of THE LaNCET.}

SIr,-I shall feel obliged by your giving insertion in Ter LANCET to an extract from a letter received by me, relative to accommodation on shipboard.-I am, Sir, your obedient servant, Jan. 10, 1850 .

F. J. B.

(EXTRACT.)

“ H.M.S. — Bashika Bay, Dec. 8th, 1849.

The Prince Regent and Thetis have left to-day, for Malta and Lisbon. The former ship demonstrates the futility of want of space for cabins for assistantsurgeons; or, at least, that this objection is entirely retrospective, and by no means prospective. Every one knows that she is of the new school of fitting and equipment, which will become common in our service. I went on board a Turk the other day, and found her fitted in the same way. The Prince Regent has an entire orlop, with cabins the whole extent, so numerous that midshipmen have washing cabins, and the captain's cook (a French artiste, on a good salary) has a cabin to himself. Why should we not, then, all have cabins?"

\section{To the Editor of The LaNCET.}

Sir,-I trust that yon will afford me space for some observations respecting the rank of naval surgeons, with other matters that also require reformation.

I do not complain of the absolute rank conferred on these gentlemen, (which is that of lieutenants in the royal navy, or of cap. tains in the army,) but of the relation invariably maintained between officers holding equal rank in the executive and civil classes. The civilian (as he is improperly called) is made to rank with, but after the executive officer. Precedency should take place according to seniority-that is, date of commission-which would be an equitable arrangement, and which would do away with the inconveniences attending the present system; one of which is location in the cockpit, in a dark cabin, as a matter of course.

Naval medical officers above the rank of surgeons do not hold equal rank with their brother officers in the army, but one step lower; and this disparity affects the director-general himself, who ranks with a brigadier-general, whilst the army directorgeneral takes rank with a major-general. Equalization of rank should take place between the medical officers of the two services, and with it, equalization of privileges, (especially in the case of the assistant-surgeons.) With such an equalized scale, the naval deputy-inspector would rank with the lieutenant-colonel in the army, and an additional rank would be granted to the naval service, to correspond with that of the major. Such a rank exists in the army in the case of the first-class staff-surgeon. The rank of major should be given to surgeons of twelve years' active service, (as is the case in the United States navy;) and such surgeons should have line-of-battle-ship and hospital appointments.

Another matter requiring inquisition is the pension given to the widows of surgeons and of the superior medical officers. It is lower than that of officers of corresponding rank in the executire class. The Medical Fund (to which the subscriptions are obligatory) does not supply a fair argument for the clipping of the pension. But granting that it does, why not then force the executive officers to pay to a fund, and clip their widows' pensions?

Medical officers are denied military rewards and distinctions. This subject, however, must be now well known to the profession and the public by means of the pamphlet entitled "Summary of the Claims of the Medical Officers of the Army and Navy to Military Rewards and Distinctions."

In concluding these observations, I would remark that the undress uniform of surgeons is so ordered that it cannot be distinguished from that of pursers, assistant-surgeons, mates, second masters, and clerks. I do not advocate distinctions in dress-on the contrary, I prefer uniformity; but whilst they exist, wardroom offeers should not be subjected to the minimum amount of respect from sentries, which they are now very likely to receive in consequence of mistakes. The truth is, Sir, the Royal Navy wants a thorough overhauling, when some of the monopolies of the privileged executive class will be broken up, to give place to a fair adjustment of the claims of all classes.

I am, Sir, your ohedient servant,

F. J. B.

January 10,1850 .

\section{To the Editor of The LanceT.}

H.M.S. - March 7, 1849 .

Str,-There is a strong disposition on the part of the Admiralty to bring forward the mates as an obstacle to the improvement re- 